\title{
Keragaman Jenis Opisthobranchia di Taman Laut 17 Pulau Riung, Nusa Tenggara Timur
}

\author{
Species Diversity of Opisthobranchia in Marine Reserve 17 Islands Riung, Nusa \\ Tenggara Timur
}

\author{
Maria M. Ngole ${ }^{1}$, Pantang K Oliva ${ }^{1}$, Felicia Zahida ${ }^{{ }^{*}}$ dan Boy R. Sidharta ${ }^{1}$ \\ ${ }^{I}$ Fakultas Biologi,Universitas Atma Jaya Yogyakarta \\ e-mail: feliciazda@mail.uajy.ac.id *penulis untuk korespondensi
}

\begin{abstract}
Penelitian inventarisasi jenis Opisthobranchia telah dilakukan untuk menunjang ekowisata di daerah Taman Laut 17 Pulau Riung. Taman laut ini terletak di kecamatan Riung, Kabupaten Ngada, Flores, Nusa Tenggara Timur. Kawasan ini di sebelah barat dibatasi oleh kabupaten Manggarai dan disebelah timur oleh desa Nggolonio, di utara dibatasi dengan laut Flores dan di selatan oleh Desa Wangka, Alo Mamek, dan Ten Terong. Areanya meliputi lima buah desa yaitu desa Lengkosambi, Tadho, Benteng Tengah, Nangamese dan Sambinasi. Secara geografis terletak antara 8'20'30" - 8'28'30" LS hingga 9055'30" $90^{\circ} 09^{\prime} 00^{\prime \prime}$ BT. Luas daratan sekitar 5 ha dan terumbu karang seluas 7.500 ha (Anonim a dan b. 1993). Opisthobranchia amat disukai oleh penyelam dan penggemar fotografi bawah laut dari mancanegara, namun masih amat sedikit penelitiannya di Indonesia.

Penelitian dilakukan di daerah intertidal dan subtidal dengan metode penjelajahan yang diupayakan proporsional dengan luas pulau. Waktu yang digunakan untuk penjelajahan diupayakan proporsional terhadap luasan pulau, dengan menggunakan kecepatan renang (snorkelling) atau penyelaman (scuba diving) yang konstan. Jenis-jenis yang ditemui dicatat dan dilakukan pemotretan. Hanya 12 pulau yang digunakan dalam survai ini yang dipilih secara acak, yaitu pulau Pata, Tajam, Dua, Rutong, Bampa Timur, Wire, Sui, Tembang, Bakau, Halimah, Lain Jawa, dan Ontoloe.

Hasil survai menunjukkan bahwa paling banyak dapat diketemukan sebanyak 17 jenis dalam satu pulau seperti pada pulau Halimah dan Ontoloe (lihat Gambar 1. dan Tabel 1.). Sementara pulau Bakau dan Lain Jawa terdapat 16 jenis. Pada pulau-pulau
\end{abstract}

lainnya jumlah jenis yang ada hanya 13 atau lebih kecil dari itu. Pulau yang memiliki paling sedikit jenis adalah pulau Dua, yaitu dengan 6 jenis. Sementara total jenis yang diketemukan pada keseluruhan pulau adalah 22 jenis. Diduga jumlah jenis yang diketemukan akan lebih banyak jika kondisi terumbu karang lebih baik, hal ini karena di masa lalu ada penangkapan ikan yang tidak bertanggung jawab (Manu. 2002 pers. comm.).

Jenis-jenis yang umum diketemukan adalah Phyllidia varicosa, Phyllidia elegans, Phyllidia tula, dan Phyllidia coelestis, jenis tersebut diketemukan pada 11-12 pulau, dilanjutkan dengan Chromodoris leopardus, Dolabella auricula, Phaneropthalmus smaragdimus, Platydoris argo, dan Phyllidiella pustulesa (Rudman, 2001, 2000, Bollands, 2005), yang diketemukan pada 7-8 pulau. Jenis-jenis yang umum ini memang memiliki adaptasi yang baik, mampu mengubah warna tubuh secara homocromi sehingga mudah terhindar dari predator (Bunckhorst, 1993, Rudman, 2001, 2000, Collier, J.R. 1983) atau suka bersembunyi di celah-celah (Potter, 2002). Sementara jenisjenis yang kurang umum dan diduga endemik adalah Aldisa Williamsy (Rudman,2002 a dan b) Phyllidia ocellata, dan Melanochlamys ezzoensis. Ketiga spesies tersebut hanya diketemukan di 2 pulau saja.

\section{Ucapan Terima Kasih}

Penulis mengucapkan terimakasih kepada WWF Nusa Tenggara dan Wallacea yang telah membantu penelitian ini di lapangan. 
Ngole, et al.

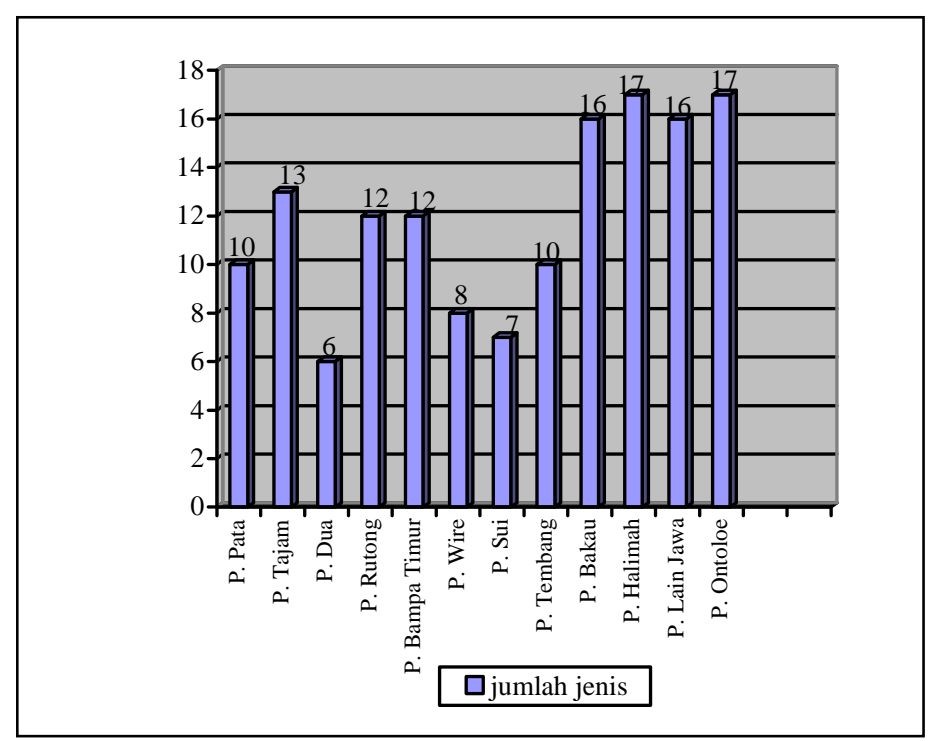

Gambar 1. Kekayaan jenis tiap pulau di Taman Nasional Laut 17 Pulau Riung, NTT.

Tabel 1. Jenis dan Sebaran Opisthobranchia yang diketemukan di Taman Nasional Laut 17 Pulau.

\begin{tabular}{|c|c|c|c|c|c|c|c|c|c|c|c|c|c|c|c|}
\hline \multirow[t]{2}{*}{ No } & \multirow[t]{2}{*}{ Jenis } & \multirow[t]{2}{*}{ Familia } & \multicolumn{13}{|c|}{ Pulau } \\
\hline & & & $\mathrm{Pt}$ & $\mathrm{Tj}$ & $\mathrm{D}$ & $\mathrm{Rt}$ & $\mathrm{BT}$ & $\mathrm{W}$ & $\mathrm{s}$ & $\mathrm{T}$ & B & $\mathrm{H}$ & $\overline{L J}$ & $\mathrm{O}$ & $\Sigma$ \\
\hline 1 & Aplysia dactylomela & Aplisiidae & - & - & - & 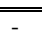 & - & - & - & $\bar{v}$ & $\bar{v}$ & $\bar{v}$ & $\bar{v}$ & $\bar{v}$ & $\overline{5}$ \\
\hline 2 & Aplysia oculifera & Aplisiidae & $\sqrt{ }$ & $\sqrt{ }$ & - & $\sqrt{ }$ & $\sqrt{ }$ & $\sqrt{ }$ & - & - & - & - & - & - & 5 \\
\hline 3 & Aldisa williamsy & Dorididae & - & - & - & - & - & - & - & - & - & - & $\sqrt{ }$ & $\sqrt{ }$ & 2 \\
\hline 4 & Chelidonora amoena & Phylinnoidae & $\sqrt{ }$ & $\sqrt{ }$ & - & $\sqrt{ }$ & $\sqrt{ }$ & - & - & - & - & - & - & - & 4 \\
\hline 5 & Chromodoris leopardus & Phyllidiidae & $\sqrt{ }$ & $\sqrt{ }$ & - & $\sqrt{ }$ & $\sqrt{ }$ & $\checkmark$ & - & - & - & $\sqrt{ }$ & $\sqrt{ }$ & $\sqrt{ }$ & 8 \\
\hline 6 & Dolabela auricula & Aplysiidae & $\sqrt{ }$ & $\sqrt{ }$ & - & $\sqrt{ }$ & $\sqrt{ }$ & - & - & $\sqrt{ }$ & $\sqrt{ }$ & $\sqrt{ }$ & - & $\sqrt{ }$ & 8 \\
\hline 7 & Melanochlamys ezzoensis & Phylinnoidae & - & - & - & - & - & - & - & - & - & $\sqrt{ }$ & - & $\sqrt{ }$ & 2 \\
\hline 8 & Phaneropthalmus smaragdimus & Platidorididae & - & $\sqrt{ }$ & - & $\sqrt{ }$ & $\sqrt{ }$ & - & - & - & $\sqrt{ }$ & $\sqrt{ }$ & $\sqrt{ }$ & $\sqrt{ }$ & 7 \\
\hline 9 & Platydoris argo & Dorididae & - & $\checkmark$ & $\sqrt{ }$ & - & $\checkmark$ & - & - & - & $\sqrt{ }$ & $\checkmark$ & $\checkmark$ & $\checkmark$ & 7 \\
\hline 10 & Phyllidia coelestis & Philidiidae & $\sqrt{ }$ & $\sqrt{ }$ & $\sqrt{ }$ & $\sqrt{ }$ & $\sqrt{ }$ & $\sqrt{ }$ & $\sqrt{ }$ & - & $\sqrt{ }$ & $\sqrt{ }$ & $\sqrt{ }$ & $\sqrt{ }$ & 11 \\
\hline 11 & Phyllidia elegans & Philidiidae & $\checkmark$ & $\sqrt{ }$ & $\sqrt{ }$ & $\checkmark$ & $\checkmark$ & $\checkmark$ & $\checkmark$ & $\sqrt{ }$ & $\checkmark$ & $\checkmark$ & $\checkmark$ & $\checkmark$ & 12 \\
\hline 12 & Phyllidia multifaria & Philidiidae & - & - & - & - & - & - & - & - & $\sqrt{ }$ & $\sqrt{ }$ & $\checkmark$ & $\sqrt{ }$ & 4 \\
\hline 13 & Phyllidia madangensis & Philidiidae & - & - & - & - & - & - & $\sqrt{ }$ & $\checkmark$ & $\checkmark$ & $\checkmark$ & $\sqrt{ }$ & - & 5 \\
\hline 14 & Phyllidia tula & Philidiidae & $\checkmark$ & $\sqrt{ }$ & - & $\sqrt{ }$ & $\checkmark$ & $\sqrt{ }$ & $\sqrt{ }$ & $\sqrt{ }$ & $\sqrt{ }$ & $\checkmark$ & $\sqrt{ }$ & $\checkmark$ & 11 \\
\hline 15 & Phyllidia varicosa & Philidiidae & $\sqrt{ }$ & $\sqrt{ }$ & $\sqrt{ }$ & $\sqrt{ }$ & $\sqrt{ }$ & $\sqrt{ }$ & $\sqrt{ }$ & $\sqrt{ }$ & $\sqrt{ }$ & $\sqrt{ }$ & $\sqrt{ }$ & $\sqrt{ }$ & 12 \\
\hline 16 & Phyllidia ocellata & Philidiidae & - & $\sqrt{ }$ & $\sqrt{ }$ & - & - & - & - & - & - & - & - & - & 2 \\
\hline 17 & Phyllidiella nigra & Philidiidae & $\sqrt{ }$ & $\sqrt{ }$ & $\checkmark$ & $\sqrt{ }$ & $\sqrt{ }$ & - & $\sqrt{ }$ & $\sqrt{ }$ & $\sqrt{ }$ & $\sqrt{ }$ & $\sqrt{ }$ & $\sqrt{ }$ & 11 \\
\hline 18 & Phyllidiella pustulosa & Philidiidae & - & - & - & - & - & $\checkmark$ & $\sqrt{ }$ & $\sqrt{ }$ & $\sqrt{ }$ & $\sqrt{ }$ & $\checkmark$ & $\sqrt{ }$ & 7 \\
\hline 19 & Phyllidiopsis kremfi & Philidiidae & - & - & - & - & - & - & - & $\checkmark$ & $\checkmark$ & $\sqrt{ }$ & $\sqrt{ }$ & $\checkmark$ & 5 \\
\hline 20 & Phyllidiopsis striata & Philidiidae & - & - & - & - & - & - & - & - & $\sqrt{ }$ & $\sqrt{ }$ & $\sqrt{ }$ & $\sqrt{ }$ & 4 \\
\hline 21 & Phyllidiopsis burni & Philidiidae & $\sqrt{ }$ & $\sqrt{ }$ & - & $\sqrt{ }$ & - & - & - & - & - & - & - & - & 3 \\
\hline 22 & Phyliniopsis lineolata & Philidiidae & - & $\sqrt{ }$ & - & $\sqrt{ }$ & $\sqrt{ }$ & - & - & - & - & - & - & - & 3 \\
\hline
\end{tabular}

Keterangan: Pt. P. Pata, Tj. P. Tajam, D. P. Dua, R. P. Rutong, BT. P. Bampa Timur, W. P. Wire, S. P. Sui, T. P. Tembang, B. P. Bakau, H. P. Halimah, LJ. P. Lain Jawa, dan O. P. Ontoloe. 
Opisthobranchia Di Taman Laut 17Pulau Riung

\section{Daftar Pustaka}

Anonim. 1993. a. Rencana Tapak Kawasan Pariwisata Riung. Arnoldus Ende. Flores.

Anonim. 1993. b. Petunjuk Pariwisata NTT. Dinas Pariwisata. Arnoldus Ende. Flores.

Brunckhorst, D.J. 1993. The Systematics and Phylogeny of Phyllidiid Nudibranchia. Monograph. Ausralia.

Bollands. R. 2005. The Okinawan Slug Site. http://rfbolland.com/okislugs//taxonomy.ht ml. 2 Januari 2005

Collier, J.R. 1983. The Biochemistry of Molluscan Development in The Mollusca: Development. Vol 3. Academic Press, Inc. New York: 253-336.
Manu, N. 2002. pers.comm. KSDA

Potter, D. 2002 Nudibranch. Nudibranch News. 3 (2): 8

Rudman, WB. 2002. a Comments on Aldisa williamsi in Sea Slug Forum. http://www.seaslug.com. 7 Agustus 2004.

Rudman, WB. 2002. b. Comments on Aplysia dactylomella in Sea Slug Forum. http://www.seaslug.com. 7 Agustus 2004.

Rudman, WB. 2001. Comments on Phyllidia varicosa or $P$. coelestis in Sea Slug Forum. http://www.seaslug.com. 7 Agustus 2004.

Rudman, WB. 2000. Comments on Opisthobranchia in Sea Slug Forum. http://www.seaslug.com. 7 Agustus 2004. 